\title{
Low Prevalence of Nodules in Rheumatoid Arthritis Patients in Kuwait: A Description and a Comparison of Patients from the Kuwait Registry for Rheumatic Diseases
}

\author{
Adeeba Al-Herz ${ }^{\mathrm{a}}$ Adel Al-Awadhi ${ }^{\mathrm{b}}$ Khulood Saleh ${ }^{\mathrm{C}}$ Waleed Al-Kandaric \\ Eman Hasan $^{\mathrm{a}}$ Aqeel Ghanem $^{\mathrm{d}}$ Fatemah Abutiban $^{\mathrm{e}}$ Ahmad Alenizi $^{\mathrm{e}}$ \\ Mohammed Hussain ${ }^{a}$ Yaser Alid Ahmad Khadrawyc ${ }^{c}$ Ammad Fazalc \\ Khaled Mokaddem ${ }^{a}$ Ajaz Zaman ${ }^{d}$ Ghada Mazloum $^{d}$ Beena Aftab \\ Najaf Haider ${ }^{\mathrm{e}}$ Youssef Bartella ${ }^{\mathrm{a}}$ Sally Hamed ${ }^{\mathrm{a}} \quad$ Ahmed Al-Saber $^{f}$

\begin{abstract}
${ }^{a}$ Rheumatology Unit, Department of Internal Medicine, Al-Amiri Hospital, b Department of Medicine, Faculty of

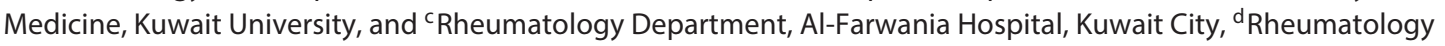
Department, Mubarak Al-Kabeer Hospital, Jabriya, ${ }^{e}$ Rheumatology Department, Al-Jahra Hospital, Al Jahra, and

fDepartment of Mathematics, Kuwait Technical College, Abu Halifa, Kuwait
\end{abstract}

\section{Key Words}

Rheumatoid nodules - Rheumatoid arthritis - Extra-articular features · Registry · Kuwait Registry for Rheumatic

Diseases $\cdot$ Kuwait · Middle East $\cdot$ Arab

\begin{abstract}
Objectives: To describe the prevalence of rheumatoid nodules (RN) in patients with rheumatoid arthritis (RA) and to compare their features with those of patients without RN. Subjects and Methods: Adult RA patients $(n=952)$ in the Kuwait Registry for Rheumatic Diseases from February 2013 to December 2015 were evaluated for RN. Demographic and serological features and disease activity and severity were obtained from the registry. Results: Of the 952 RA patients, 22 (2.3\%) had RN and 930 (97.7\%) did not. Age, sex, disease duration, smoking, and family history of an autoimmune rheumatic disease were similar. Obesity was more prevalent
\end{abstract}

\begin{tabular}{ll}
\hline KARGER & (c) 2016 S. Karger AG, Basel \\
$\begin{array}{l}\text { E-Mail karger@karger.com } \\
\text { www.karger.com/mpp }\end{array}$ & $\begin{array}{l}\text { This is an Open Access article licensed under the terms of the } \\
\text { Creative Commons Attribution-NonCommercial 3.0 Un- } \\
\text { ported license (CC BY-NC) (www.karger.com/OA-license), } \\
\text { applicable to the online version of the article only. Distribu- } \\
\text { tion permitted for non-commercial purposes only. }\end{array}$
\end{tabular}

in the RN group, i.e. 11 (50\%) vs. 326 (35.1\%), $p=0.016$. There was no difference in rheumatoid factor (RF) or anti-cyclic citrullinated peptide antibody positivity. Patients with RN had more sicca symptoms, i.e. 8 (36.4\%) vs. 152 (16.3\%), $p=$ 0.025 , a higher mean score on the visual analogue scale pain $(3 \pm 2.9$ vs. $2 \pm 2.7, p<0.001)$, more tender joints (6.4 \pm 8.8 vs. $4.2 \pm 7.2, p=0.001)$, a higher patient global assessment of disease activity $(3.3 \pm 2.7$ vs. $2.3 \pm 2.7, p<0.001)$, and more deformities, i.e. $3(13.6 \%)$ vs. 74 (8\%), $p=0.034$. The mean health assessment questionnaire score in RN patients was 1.1 versus 0.9 in patients without $\mathrm{RN}(p=0.08)$. Patients with RN had a low disease activity (means: disease activity score [DAS-28], 3.02; clinical disease activity index, 7.7; and simple disease activity index, 10.4), similar to the other group. While the rates of methotrexate treatment were comparable, biologic therapy was administered more in patients with RN (i.e. 15 [68.2\%] vs. 478 [51.4\%], $p<0.001)$. Conclusion: In Kuwait, the prevalence of RN is low among RA patients. Patients with 
and without RN are similar in terms of demographics and serologic features, except for more obesity. However, patients with RN have more sicca symptoms, joint deformities, and painful and tender joints. Disease activity scores are low with more frequent biologic therapy. $\quad \odot 2016 \mathrm{~S}$. Karger AG, Basel

\section{Introduction}

Rheumatoid nodules (RN) are subcutaneous swellings found almost exclusively in patients with rheumatoid arthritis (RA), consisting of palisading granuloma with necrotic centers. They are considered among the most common extra-articular manifestations of RA, reported in $30-40 \%$ of patients [1]. RN have been found to be associated with a more severe and progressive form of RA [1], positivity for rheumatoid factor (RF) [2], positivity for anti-cyclic citrullinated peptide antibodies (ACPA) [3], extra-articular features such as sicca symptoms, and impaired physical functions $[4,5]$. An association of methotrexate treatment with the development and progression of $\mathrm{RN}$ has been reported [6]. However, data from Arab and Middle Eastern countries are scarce and the majority of data come from Western countries [7]. Hence, in this study the objectives were to describe the prevalence of RN in patients with RA in Kuwait, to compare their features with those of patients without RN, including demographic and serologic features, and to study the association of $\mathrm{RN}$ with the activity and severity of the disease.

\section{Subjects and Methods}

\section{Subjects}

A total of 952 adult patients with RA from the Kuwait Registry for Rheumatic Diseases (KRRD), an ongoing registry of RA patients in Kuwait, were included in this study. The registry included patients who satisfied the American College of Rheumatology criteria for RA [8] from the Departments of Rheumatology of 4 of the 6 major government hospitals in Kuwait, i.e. Al-Amiri, Al-Farwania, Mubarak Al-Kabeer, and Al-Jahra Hospitals, from February 2013 through December 2015.

As part of the registry protocol, all patients were examined for $\mathrm{RN}$ during enrollment and follow-up visits to the hospitals. Their medical records were also reviewed for a report of $\mathrm{RN}$ at any point of their disease course. Thus, the cumulative occurrence of $\mathrm{RN}$ was explored since the development of RA. For the purpose of this study, if, at any time, RN was observed, the patient was labelled as "with RN". If the patient, however, did not develop RN at any time, then the patient was labelled as "without RN". Demographic, serologic, and clinical features were obtained from the registry and a comparison was made between patients with and without RN.

Low Prevalence of Nodules in RA Patients in Kuwait

\section{Methods}

As part of the registry protocol, demographic and baseline medical data, including family history, smoking history, body mass index (BMI), and serology, were recorded for all patients at their first visit to the rheumatologist. During the consecutive follow-up visits, clinical and laboratory data were measured and reported, including data on disease activity and the treatment protocol. Data included in the registry were collected by rheumatologists and trained nurses through patient interviews and clinical examinations and from medical records.

BMI were classified according to the World Health Organization [9], and obesity was defined as a BMI $\geq 30$. Serological tests, which were part of the registry, were performed using the same laboratory methods in the 4 participating hospitals as follows: IgM RF was quantitatively measured using nephelometry, and measurements above 20 were considered positive; IgG ACPA was determined using an enzyme-linked immunosorbent assay (ELISA) with a cutoff point of $20 \mathrm{U} / \mathrm{ml}$. Anti-nuclear antibodies were assessed by the indirect immunofluorescence using an Hep 2 cell line and patients were considered positive when the titer was more than $1: 40$.

The disease activity score (DAS-28) [10], the clinical disease activity index (CDAI) [11], and the simple disease activity index (SDAI) [12] were used to assess disease activity. Physical function was assessed using a health assessment questionnaire (HAQ) [13]. The mean score for each measurement tool was taken for each patient throughout the registry period. The means and individual elements of each tool were compared.

The KRRD, from which this study originated, was approved by the Ethics Committees of the Faculty of Medicine, Kuwait University, and the Ministry of Health, Kuwait. Written informed consent was obtained from the patients enrolled into the registry.

\section{Statistical Analysis}

Descriptive data analysis was used to evaluate means, SD, confidence intervals, percentages, and frequencies of distributions for the following variables: gender, age, disease duration, family history, smoking, and obesity. A $\chi^{2}$ test was used to assess the statistical significance of associations between categorical variables. An independent 2-sample $t$ test was used to assess the significance between means. Spearman's correlation test was used to assess the correlation between categorical and numerical variables. $p<0.05$ was considered statistically significant. Statistical analyses were done using the Statistical Package for the Social Sciences (SPSS), version 23.0.

\section{Results}

\section{Demographic and Serological Features}

Of the 952 patients with RA, 22 (2.3\%) had RN and $930(97.7 \%)$ did not. Of the 22 patients with RN, 14 $(63.6 \%)$ were female and $8(36.7 \%)$ were male. Of the patients without $\mathrm{RN}, 660$ (71\%) were female and 270 (27.0\%) were male ( $p=0.452$; table 1$)$. The mean age of the patients with RN was $54 \pm 12$ years, compared to 49.8 \pm 12 years for those without $\mathrm{RN}(p=0.551)$; the mean 
Table 1. Comparison of demographic and serologic features between RA patients with and without RN

\begin{tabular}{lccl}
\hline Characteristics & $\begin{array}{l}\text { With RN } \\
(n=22)\end{array}$ & $\begin{array}{l}\text { Without RN } \\
(n=930)\end{array}$ & $\begin{array}{l}p \\
\text { value }\end{array}$ \\
\hline Females & $14(63.6)$ & $660(71)$ & 0.452 \\
Males & $8(36.4)$ & $270(29)$ & \\
Age, years & $54 \pm 12$ & $49.8 \pm 12$ & 0.551 \\
Disease duration, years & $6.3 \pm 7.8$ & $6 \pm 6.4$ & 0.600 \\
F/H & $7(31.8)$ & $157(16.9)$ & 0.289 \\
Smoking & $3(13.6)$ & $99(10.6)$ & 0.673 \\
Obesity & $11(50)$ & $326(35.1)$ & $0.016^{*}$ \\
RF positivity & $17(77.3)$ & $699(75.2)$ & 0.952 \\
ACPA positivity & $11(50)$ & $542(58.3)$ & 0.482 \\
ANA positivity & $4(18.2)$ & $227(24.4)$ & 0.605 \\
\hline
\end{tabular}

Values are presented as numbers (\%) or means \pm SD unless otherwise stated. RN, rheumatoid nodules; $\mathrm{F} / \mathrm{H}$, family history of autoimmune rheumatic disease; RF, rheumatoid factor; ACPA, anti-cyclic citrullinated peptide antibodies; ANA, anti-nuclear antibodies. * Statistically significant.

disease duration in patients with $\mathrm{RN}$ was $6.3 \pm 7.8$ years, compared to $6.0 \pm 6.4$ years for patients without $\mathrm{RN}(p=$ $0.600)$. Of the 22 patients with RN, 7 (31.8\%) reported at least one first-degree relative with an autoimmune rheumatic disease, compared to 157 of the 930 (16.9\%) patients without $\mathrm{RN}$, and the difference was not statistically significant $(p=0.289)$. Of the 22 patients with $\mathrm{RN}$, $3(13.6 \%)$ were smokers, compared to $99(10.6 \%)$ patients without $\mathrm{RN}(p=0.673)$. Eleven (50\%) patients with RN were obese, compared to 326 (35.1\%) patients without RN ( $p=0.016)$.

Serological tests were similar in both groups. RF was positive in 17 (77.3\%) patients with RN versus 699 (75.2\%) patients without RN; ACPA was positive in 11 (50\%) patients with $\mathrm{RN}$ versus 542 (58.3\%) patients without RN, and anti-nuclear antibodies in were positive in 4 (18.2\%) patients with RN versus 227 (24.4\%) patients without RN.

\section{Disease Activity, Functional Assessment, and \\ Treatment}

With regard to disease activity, patients with $\mathrm{RN}$ had a mean DAS-28 score of $3.02 \pm 1.4$, compared to $2.86 \pm$ 1.33 for patients without $\mathrm{RN}(p=0.135$; table 2$)$; the mean CDAI of patients with $\mathrm{RN}$ was $7.7 \pm 8.8$, compared to $7.0 \pm 7.9$ for patients without $\mathrm{RN}(p=0.601)$, and the mean SDAI of patients with $\mathrm{RN}$ was $10.4 \pm 10.8$, compared to $10.0 \pm 10.4$ for patients without $\mathrm{RN}(p=0.779)$, indicating a low disease activity state for both groups.
Table 2. Comparison of clinical features between RA patients with and without RN

\begin{tabular}{lccc}
\hline Characteristics & $\begin{array}{c}\text { With RN } \\
(n=22)\end{array}$ & $\begin{array}{l}\text { Without RN } \\
(n=930)\end{array}$ & $\begin{array}{l}p \\
\text { value }\end{array}$ \\
\hline DAS-28 & $3.02 \pm 1.4$ & $2.86 \pm 1.33$ & 0.135 \\
CDAI & $7.7 \pm 8.8$ & $7 \pm 7.9$ & 0.601 \\
SDAI & $10.4 \pm 10.8$ & $10 \pm 10.4$ & 0.779 \\
ESR, mm/h & $22.8 \pm 19.3$ & $24.8 \pm 16.6$ & 0.238 \\
Number of swollen joints & $0.51 \pm 2.1$ & $0.57 \pm 2.2$ & 0.754 \\
VAS pain & $3 \pm 2.9$ & $2 \pm 2.7$ & $<0.001^{*}$ \\
Number of tender joints & $6.4 \pm 8.8$ & $4.2 \pm 7.2$ & $0.001^{*}$ \\
Patient's global assessment & $3.3+2.7$ & $2.3+2.7$ & $<0.001^{*}$ \\
Physician's global assessment & $1.9+2.1$ & $1.4+2.0$ & $0.017^{*}$ \\
HAQ & $1.1 \pm 0.8$ & $0.9 \pm 0.7$ & 0.082 \\
Sicca symptoms & $8(36.4)$ & $152(16.3)$ & $0.025^{*}$ \\
Deformities & $3(13.6)$ & $74(8.0)$ & $0.034^{*}$ \\
Methotrexate therapy & $8(36.4)$ & $341(36.7)$ & 0.838 \\
Methotrexate dose, mg & $15 \pm 3.8$ & $15.4 \pm 4$ & 0.387 \\
Biologic therapy & $15(68.2)$ & $478(51.4)$ & $<0.001^{*}$ \\
\hline
\end{tabular}

Values are presented as numbers (\%) or means \pm SD unless otherwise stated. RN, rheumatoid nodules; DAS-28, disease activity score; CDAI, clinical disease activity index; SDAI, simple disease activity index; ESR, erythrocyte sedimentation rate; VAS, visual analogue scale; HAQ, health assessment questionnaire. ${ }^{*}$ Statistically significant.

Erythrocyte sedimentation rates were comparable between patients with and without RN (mean \pm SD: $22.8 \pm$ 19.3 vs. $24.8 \pm 16.6$, respectively; $p=0.238$ ), as were the numbers of swollen joints $(0.51 \pm 2.1$ vs. $0.57 \pm 2.2$; $p=$ $0.754)$. Sicca symptoms, however, were reported more in patients with $\mathrm{RN}$ than in patients without $\mathrm{RN}$ (i.e., 8 [36.4\%] and 152 [16.3\%], respectively; $p=0.025$ ) and there were more deformities in patients with $\mathrm{RN}$ than in those without (i.e., 3 [13.6\%] and 74 [8\%], $p=0.034$ ). Other variables that were significantly higher in the RN group compared to patients without $\mathrm{RN}$ included: the visual analog scale (VAS) score for pain $(3 \pm 2.9$ vs. $2 \pm 2.7$, $p<0.001)$, the number of tender joints ( $6.4 \pm 8.8$ vs. $4.2 \pm$ $7.2, p=0.001)$, the patient's global assessment of disease activity ( $3.3 \pm 2.7$ vs. $2.3 \pm 2.7, p<0.001)$, and the physician's global assessment of disease activity ( $1.9 \pm 2.1$ vs. $1.4 \pm 2.0, p=0.017)$. There was a trend toward a higher HAQ in the RN group ( $1.1 \pm 0.8$ vs. $0.9 \pm 0.7, p=0.082)$.

The use of methotrexate was comparable between patients with and without RN, i.e., 8 (36.4\%) vs. 341 (36.7\%), $p=0.838$, as were the doses of methotrexate (a weekly dose of 7.5-20 mg in the RN group compared to 7.5-25 $\mathrm{mg}$ in the group without $\mathrm{RN}$; means $\pm \mathrm{SD}: 15 \pm 3.8$ and 
$15.4 \pm 4$, respectively; $p=0.387$ ). There were, however, more patients on biologic therapy in the $\mathrm{RN}$ group than in the group of patients without RN (i.e., 15 [68.2\%] vs. 478 [51.4\%], respectively; $p<0.001)$.

\section{Discussion}

In this study, the prevalence of RN was low (2.3\%), and it confirmed the RN prevalence of 3-15.9\% among patients with RA in Saudi Arabia $[14,15]$, the prevalence of $4 \%$ in the United Arab Emirates [16], the prevalence of $9 \%$ in a previous study of Kuwait [17], and that of $14.7 \%$ in Turkey [18]. However, studies from Western countries have shown a $30-40 \%$ higher prevalence of $\mathrm{RN}[2,19-$ 21]. A probable explanation for the low prevalence of $\mathrm{RN}$ in RA patients found in this study compared to the high prevalence rates of $\mathrm{RN}$ found in other studies [2,19-21] could be genetic differences in the study population since RA has been linked to HLA polymorphism and to genetic differences among different populations [22].

While smoking was not shown to be associated with $\mathrm{RN}$ in our study, Nyhall-Wahlin et al. [23] reported that $86 \%$ of patients with $\mathrm{RN}$ smoked, compared to $59 \%$ of the controls. This difference could be due to the inclusion of only current smokers in this study, as compared to patients who ever smoked in the previous study [23].

In this study, the finding that there was no association between RN and positivity for RF and ACPA was in contrast to a previous study [24] that reported such an association in spite of the similar prevalence of RF and ACPA in patients with RA in Kuwait compared to other populations [25]. This may raise questions regarding the previously proposed role of autoantibodies in the formation of $\mathrm{RN}$ in patients with RA.

The finding that approximately half of the RA patients with $\mathrm{RN}$ in this study were obese could indicate a probable role of obesity in the formation of $\mathrm{RN}$, an association that has never previously been described. It is important to further explore obesity and its association with $\mathrm{RN}$ as obesity and RN are risk factors for aggressive RA [1, 5, 26], but obesity is also a well-known risk factor for associated comorbidities such as cardiovascular diseases [27, 28 ] and should carefully be taken into consideration in such patients. Similar to what has previously been reported, patients with $\mathrm{RN}$ had a more deforming disease and a higher frequency of sicca symptoms [1].

The results indicate that use of methotrexate was comparable in patients with $\mathrm{RN}$ (36.4\%) and those without (36.7\%), although it has previously been reported that methotrexate therapy could induce RN [6]. The lack of an association between RN and methotrexate use in our population may suggest that factors other than methotrexate, such as the disease itself, could be responsible for the development of RN. The association between biologic therapy and RN in this study could either be explained by the induction of $\mathrm{RN}$ by biologic therapy, as was previously reported $[29,30]$, or it could be related to the tendency of the rheumatologists to aggressively treat patients with $\mathrm{RN}$ with such potent therapy.

Comparable disease activity scores, including DAS-28, CDAI, and SDAI, between the 2 groups may reflect the aggressive therapeutic approach used for patients with $\mathrm{RN}$ given that biologic therapy was more prescribed for such patients in this study. Increased joint tenderness and the subjective patient's assessment of pain and of disease activity might be related to the presence of more deformed joints, which might also have affected the patients' physical functions as measured by the HAQ. This could also have influenced the physician's scoring of disease activity given the joint pain and tenderness.

\section{Conclusion}

In this study, the prevalence of RN was low among patients with RA in Kuwait. The patients with RN had similar demographic and serologic features and a similar use of methotrexate. The RN patients had a higher BMI, more joint deformities, more painful and tender joints, and possibly more limitations in physical functions. However, they had a low disease activity state with more use of biologic therapy. The factors behind the paucity of RN in Kuwait and their influence on the severity and prognosis of the disease need further exploration.

\section{Acknowledgment}

The authors would like to thank all of those who have contributed in data collection and data processing for the registry. Without them, this study will not have been possible.

\section{Disclosure Statement}

This is an investigational study from the Kuwait Registry for Rheumatic Diseases. The Kuwait Registry for Rheumatic Diseases is supported by an unconditional grant from Pfizer, Gulf Region, Dubai. 


\section{References}

1 Nyhall-Wahlin BM, Turesson C, Jacobsson LT, et al: The presence of rheumatoid nodules at early rheumatoid arthritis diagnosis is a sign of extra-articular disease and predicts radiographic progression of joint destruction over 5 years. Scand J Rheumatol 2011;40:8187.

2 Sayah A, English JC 3rd: Rheumatoid arthritis: a review of the cutaneous manifestations. J Am Acad Dermatol 2005;53:191-209.

3 Kim SK, Park SH, Shin IH, et al: Anti-cyclic citrullinated peptide antibody, smoking, alcohol consumption, and disease duration as risk factors for extraarticular manifestations in Korean patients with rheumatoid arthritis. J Rheumatol 2008;35:995-1001.

4 Turesson C, McClelland RL, Christianson T, et al: Clustering of extraarticular manifestations in patients with rheumatoid arthritis. J Rheumatol 2008;35:179-180.

5 Yuan S, Chen D, Xiao Y, et al: Factors associated with erosive arthritis in rheumatoid arthritis and other connective tissue diseases: a retrospective study from a Southern Chinese population. J Clin Rheumatol 2016;22:22-29.

6 Merrill JT, Shen C, Schreibman D, et al: Adenosine A1 receptor promotion of multinucleated giant cell formation by human monocytes: a mechanism for methotrexateinduced nodulosis in rheumatoid arthritis. Arthritis Rheum 1997;40:1308-1315.

7 Cheng T, Zhang G: Worldwide research productivity in the field of rheumatology from 1996 to 2010:a bibliometric analysis. Rheumatology (Oxford) 2013;52:1630-1634.

8 Aletaha D, Neogi T, Silman AJ, et al: 2010 Rheumatoid arthritis classification criteria: an American College of Rheumatology/European League against Rheumatism collaborative initiative. Arthritis Rheum 2010;62: 2569-2581.

9 Physical status: the use and interpretation of anthropometry - report of a WHO Expert Committee. World Health Organ Tech Rep Ser 1995;854:1-452.

10 Prevoo ML, van 't Hof MA, Kuper HH, et al: Modified disease activity scores that include twenty-eight-joint counts: development and validation in a prospective longitudinal study of patients with rheumatoid arthritis. Arthritis Rheum 1995;38:44-48.

11 Aletaha D, Nell VP, Stamm T, et al: Acute phase reactants add little to composite disease activity indices for rheumatoid arthritis: validation of a clinical activity score. Arthritis Res Ther 2005;7:R796-R806.

12 Smolen JS, Breedveld FC, Schiff MH, et al: A simplified disease activity index for rheumatoid arthritis for use in clinical practice. Rheumatology (Oxford) 2003;42:244-257.

13 Linde L, Sorensen J, Ostergaard M, et al: Health-related quality of life: validity, reliability, and responsiveness of SF-36, 15D, EQ-5D (corrected) RAQoL, and HAQ in patients with rheumatoid arthritis. J Rheumatol 2008; 35:1528-1537.

14 Alballa SR: The expression of rheumatoid arthritis in Saudi Arabia. Clin Rheumatol 1995; 14:641-645.

15 Al-Ghamdi A, Attar SM: Extra-articular manifestations of rheumatoid arthritis: a hospitalbased study. Ann Saudi Med 2009;29:189193.

16 Badsha H, Kong KO, Tak PP: Rheumatoid arthritis in the United Arab Emirates. Clin Rheumatol 2008;27:739-742.

17 Al-Salem IH, Al-Awadhi AM: The expression of rheumatoid arthritis in Kuwaiti patients in an outpatient hospital-based practice. Med Princ Pract 2004; 13:47-50.

18 Eser F, Garip Y, Bodur H: Extraarticular manifestations in Turkish patients with rheumatoid arthritis: impact of EAMs on the healthrelated quality of life in terms of disease activity, functional status, severity of pain, and social and emotional functioning. Rheumatol Int 2012;32:1521-1525.

19 Highton J, Hessian PA, Stamp L: The rheumatoid nodule: peripheral or central to rheumatoid arthritis? Rheumatology (Oxford) 2007; 46:1385-1387.

20 Myasoedova E, Crowson CS, Turesson C, et al: Incidence of extraarticular rheumatoid arthritis in Olmsted County, Minnesota, in
1995-2007 versus 1985-1994: a populationbased study. J Rheumatol 2011;38:983-989.

21 Turesson C, Jacobsson LT: Epidemiology of extra-articular manifestations in rheumatoid arthritis. Scand J Rheumatol 2004;33:65-72.

22 Cadena J, Anaya J-M: Clinical comparisons of RA between different populations: are they feasible? Ann Rheum Dis 2003;62:1124-1125.

23 Nyhall-Wahlin BM, Jacobsson LT, Petersson IF, et al: Smoking is a strong risk factor for rheumatoid nodules in early rheumatoid arthritis. Ann Rheum Dis 2006;65:601-606.

24 Gonzalez-Lopez L, Rocha-Munoz AD, PonceGuarneros M, et al: Anti-cyclic citrullinated peptide (anti-CCP) and anti-mutated citrullinated vimentin (anti-MCV) relation with extra-articular manifestations in rheumatoid arthritis. J Immunol Res 2014;2014:536050.

25 Al-Herz A, Saleh K, Al-Awadhi A, et al: A comparison of rheumatoid arthritis patients in Kuwait with other populations: results from the KRRD registry. Br J Med Med Res 2016;14:1-11.

26 Stavropoulos-Kalinoglou A, Metsios GS, Panoulas VF, et al: Underweight and obese states both associate with worse disease activity and physical function in patients with established rheumatoid arthritis. Clin Rheumatol 2009; 28:439-444.

27 Kremers HM, Crowson CS, Therneau TM, et al: High ten-year risk of cardiovascular disease in newly diagnosed rheumatoid arthritis patients: a population-based cohort study. Arthritis Rheum 2008:58:2268-2274.

28 Kaushik P, Solomon DH, Greenberg JD, et al: Subcutaneous nodules are associated with cardiovascular events in patients with rheumatoid arthritis: results from a large US registry. Clin Rheumatol 2015;34:1697-1704.

29 Kovacs A, Baksay B, Cserenyecz A, et al: Occurrence of pulmonary rheumatoid nodules following biological therapies. Clin Rheumatol 2015;34:1639-1642.

30 Mackley CL, Ostrov BE, Ioffreda MD: Accelerated cutaneous nodulosis during infliximab therapy in a patient with rheumatoid arthritis. J Clin Rheumatol 2004;10:336-338. 